\title{
Cineteca Teatro Carrera
}

\section{PREÁMBULO}

A partir de la intervención sobre el ex Teatro Carrera, Monumento Histórico Nacional, el siguiente proyecto plantea la problemática de la recuperación de edificios obsoletos. Una aproximación que nos permite reflexionar en torno a las intervenciones contemporáneas sobre arquitecturas del pasado. En el caso de esta propuesta, no solo se recupera el objeto arquitectónico, sino también su presencia como punto de activación social y cultural.

\footnotetext{
| ABSTRACT |

From the intervention of the former Carrera Theatre, a national historic monument, this project raises the issue of the recovery of obsolete buildings. An approach that allows us to reflect on the contemporary interventions on the architecture of the past. In the case of this proposal, it not only recovers the architectural object, but also its presence as a point of social and cultural activation.
}

El proyecto nace a partir de la fascinación personal por re-arquitecturizaciones de infraestructuras obsoletas, donde pasado y presente se intersectan formal y constructivamente de tal manera de suturar la grieta que existe entre lo que el edificio fue y lo que puede llegar a ser hoy en día.

Como dice Kenneth Powell "de la necesidad surge la intervención, de ahí los proyectos de salvar el edificio, de la conservación se ha pasado hoy en día a la transformación, un punto de vista más arquitectónico que sentimental o historicista de crear nuevas formas a partir de construcciones anteriores". Bajo este carácter y perspectiva transformista se formula este proyecto de arquitectura.

\section{INTRODUCCIÓN}

A comienzos del siglo XX, los cines y teatros constituyen el espacio representativo de recreación colectiva y anónima, llegando a ser en la década del 20 y 30 la principal distracción de los ciudadanos; dentro de sus funciones se incluían dibujos animados, noticias del mundo y espectáculos en vivo. Debido a la buena acogida que tuvo por parte de la multitud, esta tipología arquitectónica -de gran presencia urbana- se insertó en lugares específicos de la ciudad.

Sin embargo, la mayoría de estos contenedores de vida urbana hoy en día se encuentran obsoletos; en estado de abandono, subutilizados o simplemente demolidos. Estas estructuras que aún forman parte de la realidad física de la ciudad, se presentan descontextualizadas, sin un rol definido dentro de la actividad actual de este sistema. Al no incorporarse funcional y programáticamente, quedan como una huella en la trama urbana de una actividad colectiva memorable perdida en el tiempo.

Como punto de partida se plantea una hipótesis que relaciona los espacios vacíos que dejaron los cines de barrio y la posibilidad de reintegrarlos programática y espacialmente a la actividad urbana actual. Dicho esto, la intención que persigue este proyecto es equilibrar el valor patrimonial histórico que tiene el edificio 
1. Esquema.

(1)

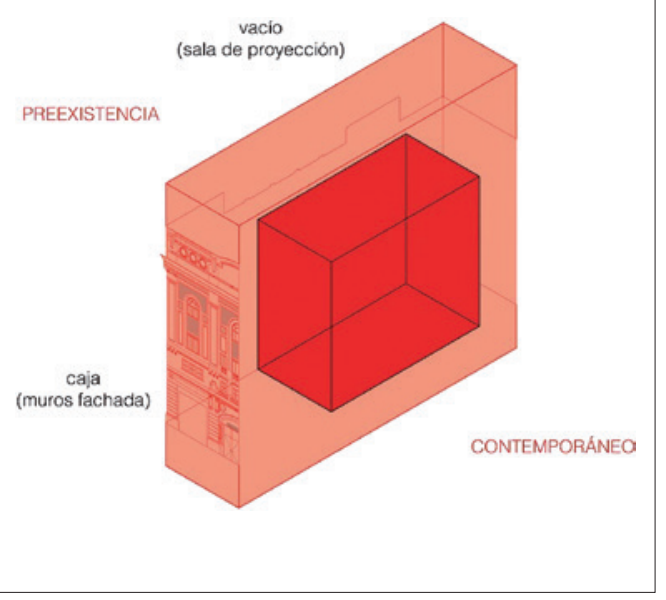

existente y las virtudes que puede adquirir al someterlo a un fenómeno transformativo que permita reintegrarlo programática y físicamente a la vida de hoy. Es así, como el proyecto se desarrolla bajo la premisa de la re-arquitecturización de infraestructura urbana obsoleta.

Esta situación motiva la reflexión sobre su reinserción en el presente, planteando un punto de tensión entre el carácter histórico -lo que fue y la expresión tangible de ello-y lo que puede llegar a ser a través de su recuperación. Gracias a la resistencia que estos espacios poseen, perduran en condiciones de congelamiento temporal, cuya condición se manifiesta como una oportunidad de proyecto arquitectónico.

El ex Teatro Carrera -declarado Monumento Histórico Nacional en 1989-será el elemento y matriz de diseño para entender la rearquitecturización y re-significación de los cines de barrio como activadores urbanos en la ciudad.

2. Operaciones espaciales.

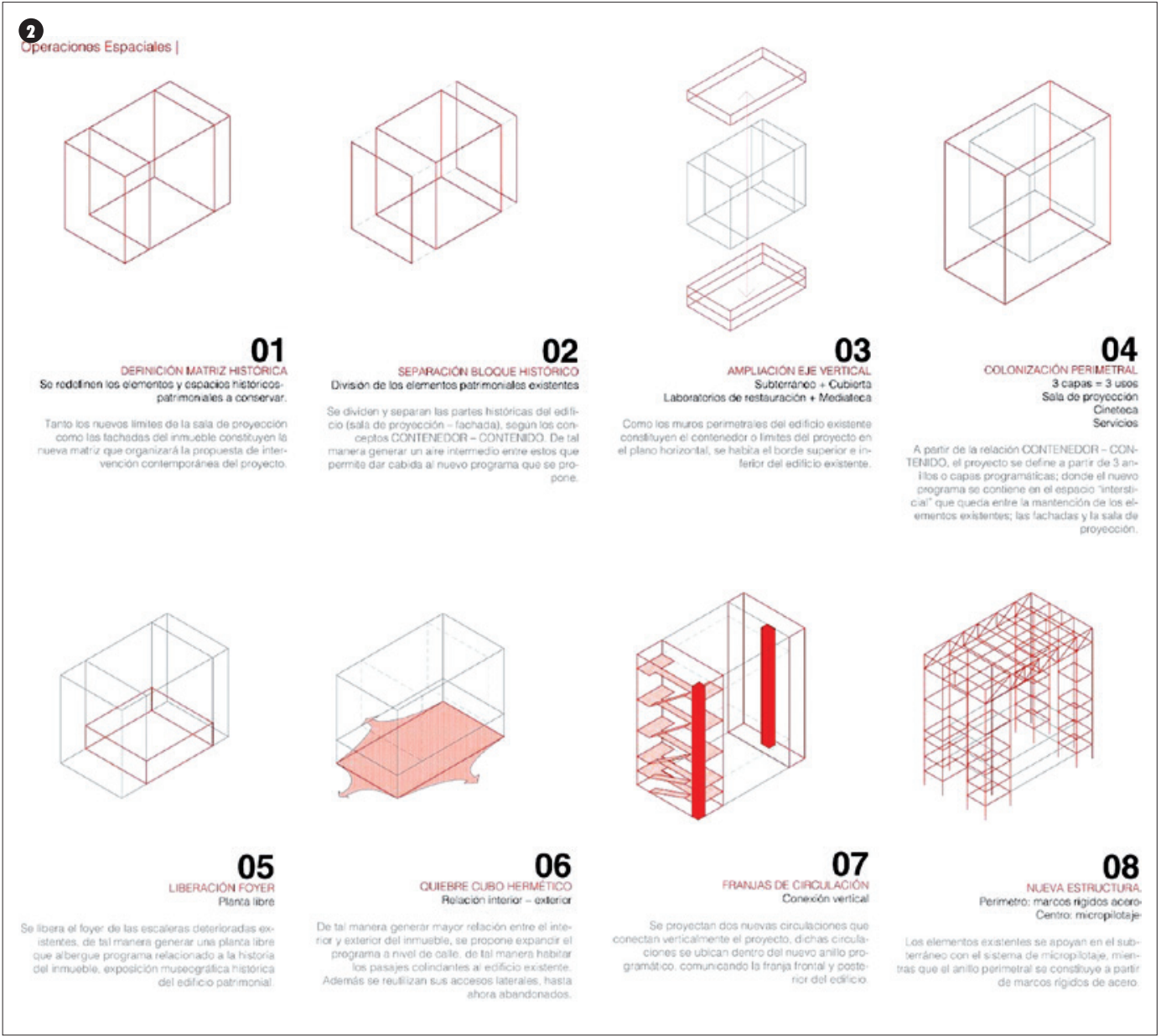

\section{PROBLEMÁTICAS}

PROBLEMÁTICA 1. El estado de abandono y desuso de inmuebles patrimoniales

Edificios históricos patrimoniales ajenos a la actividad urbana actual (obsoletos funcionalmente), que producto de la perdurabilidad de su forma no satisfacen las necesidades del habitante contemporáneo, siendo su fin último el abandono o demolición.

Si bien se reconoce la importancia y aporte de las construcciones antiguas como elementos de la ciudad, es innegable la necesidad de mantenerlos con vida, es decir, utilizar, habitar estos espacios de tal manera que puedan ser reincorporados a la actividad urbana actual, de otra forma seguiremos perdiendo progresivamente este legado arquitectónico y urbano.

PROBLEMÁTICA 2. Intervención contemporánea en edificios antiguos

Restauración y Reciclaje, dos caminos diferentes para un mismo objetivo; preservación del patrimonio urbano. Esta disyuntiva genera un debate teórico respecto a la manera de cómo enfrentarse a este elemento o matriz edilicia existente, es más que nada una defensa de posturas entre la visión conservacionista y más radical de la intervención en obras existentes, más aún cuando esta tiene reconocimiento y valor histórico. 
3. Emplazamiento.
3

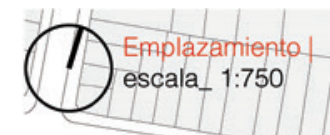

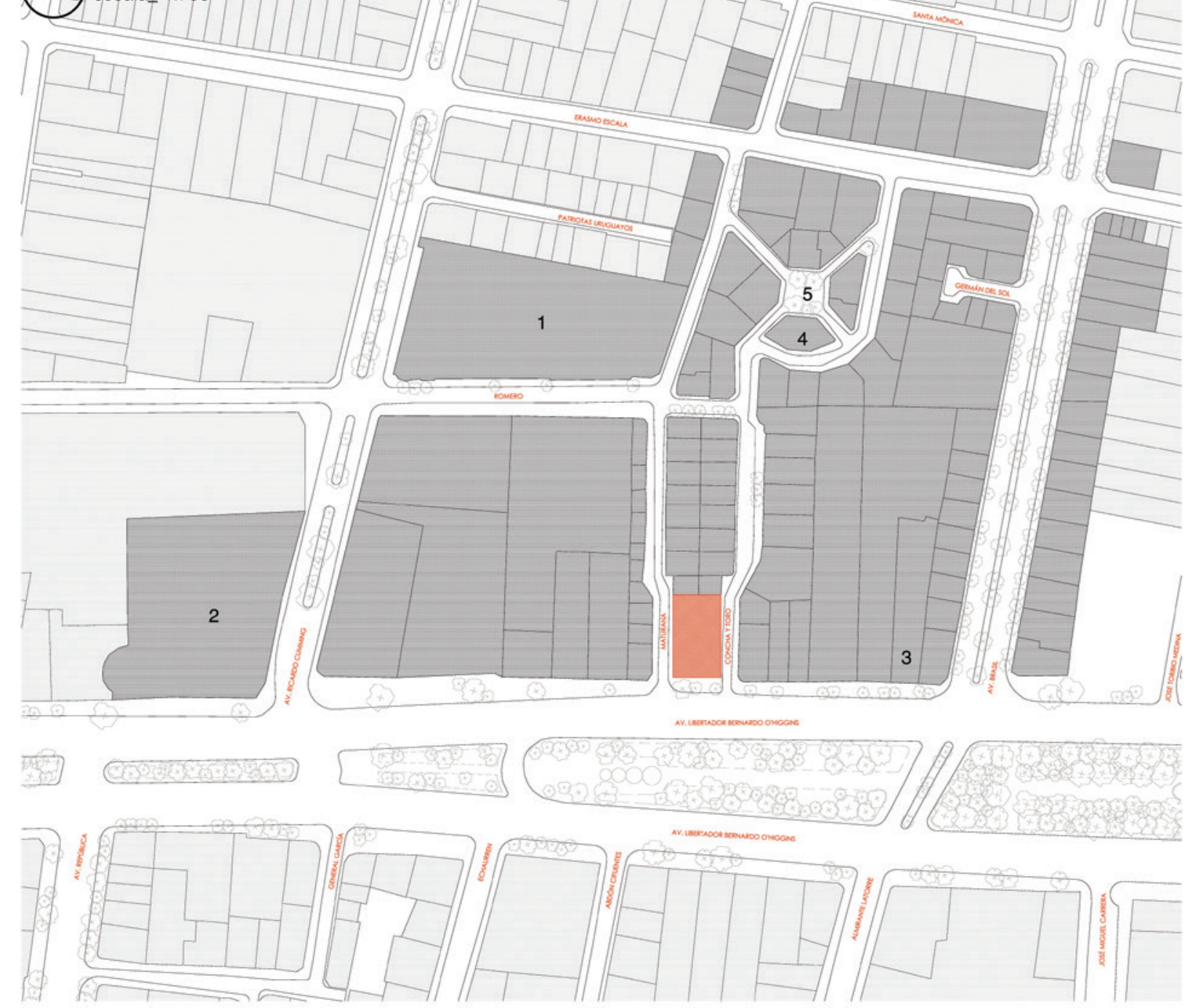

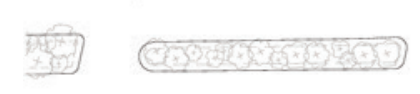

7
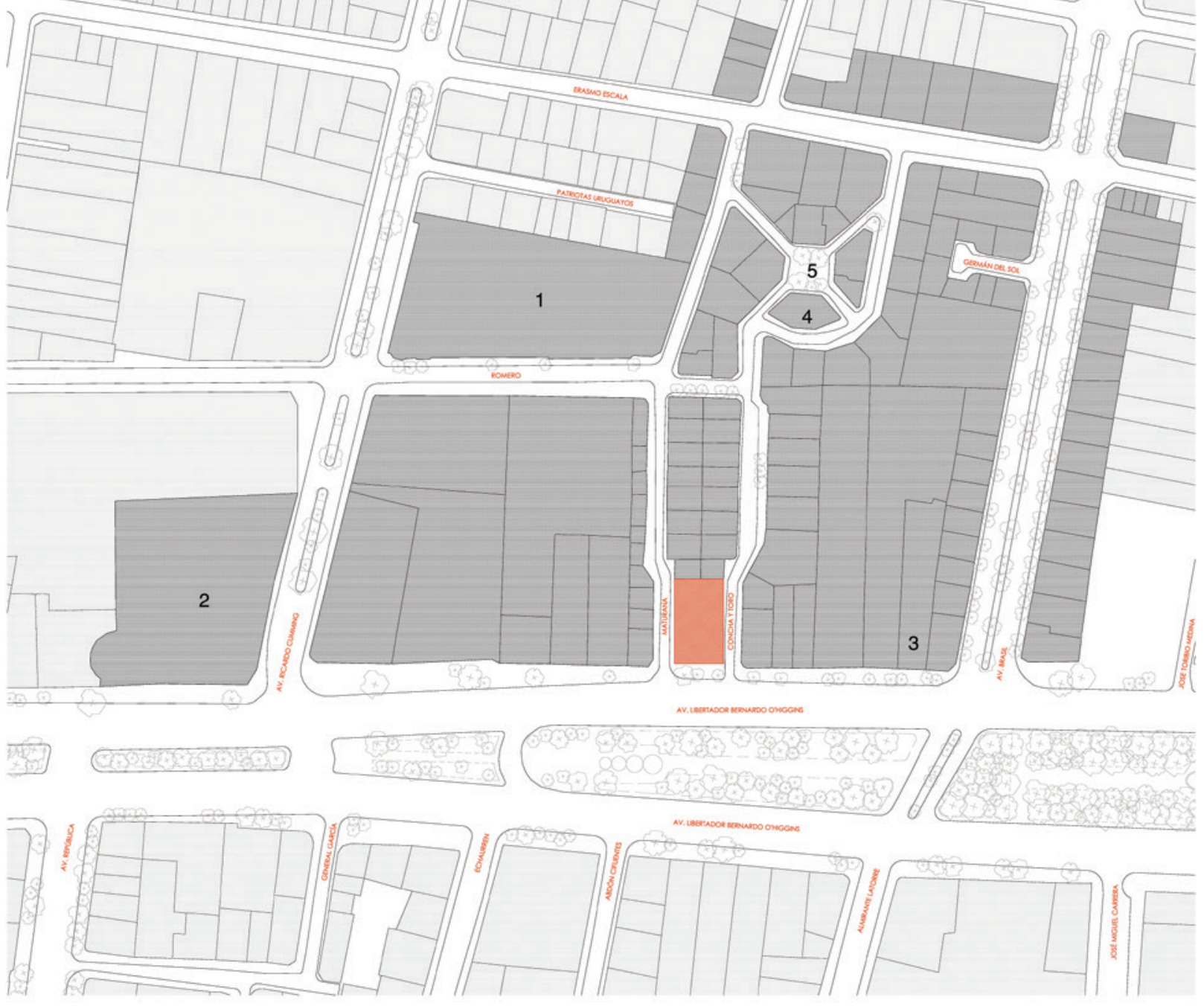
71
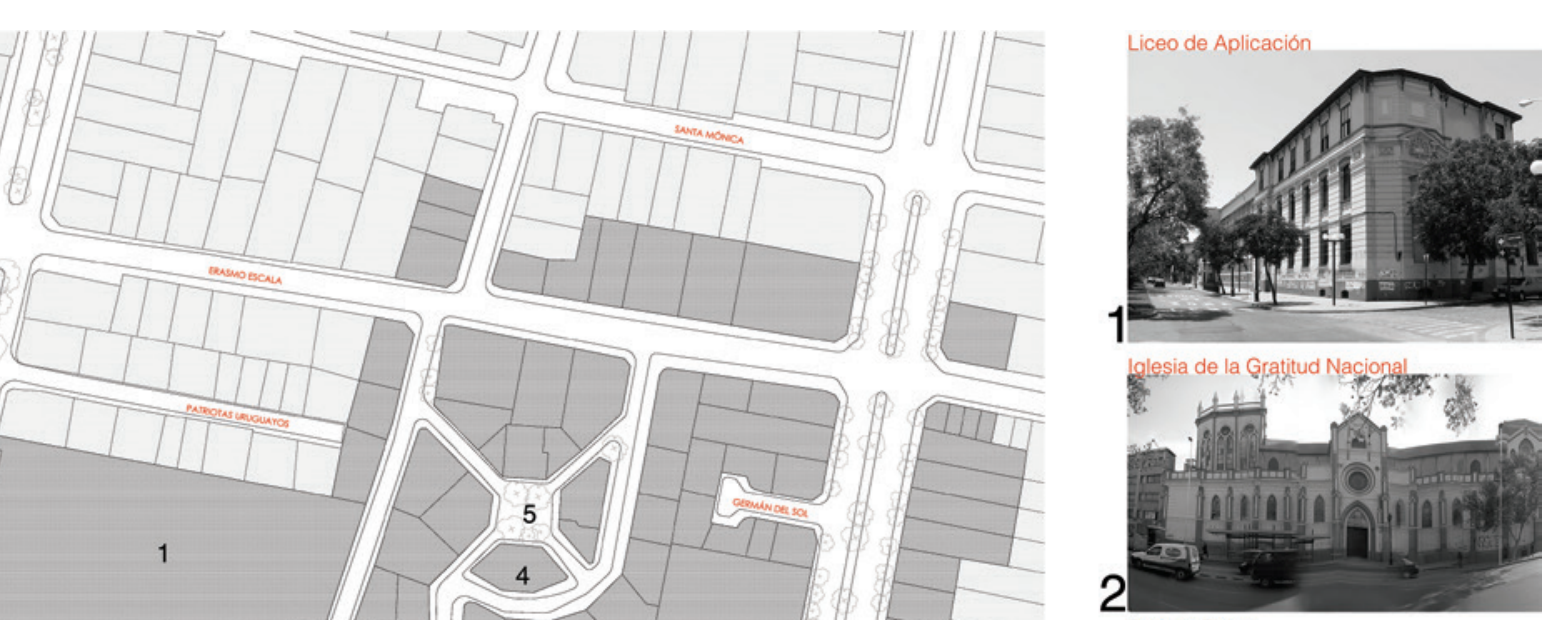

Palacio Elguín
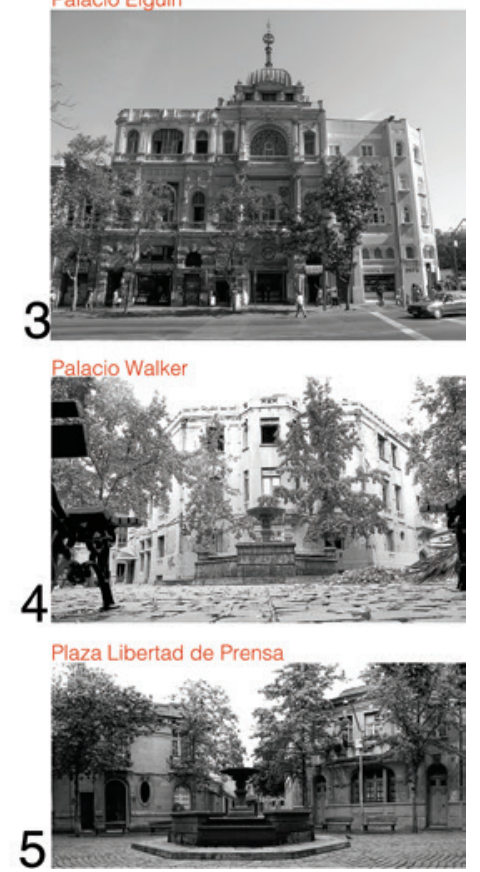
4. Situación actual Teatro Carrera. Fuente: Álvaro Mardones Saint-Jean.

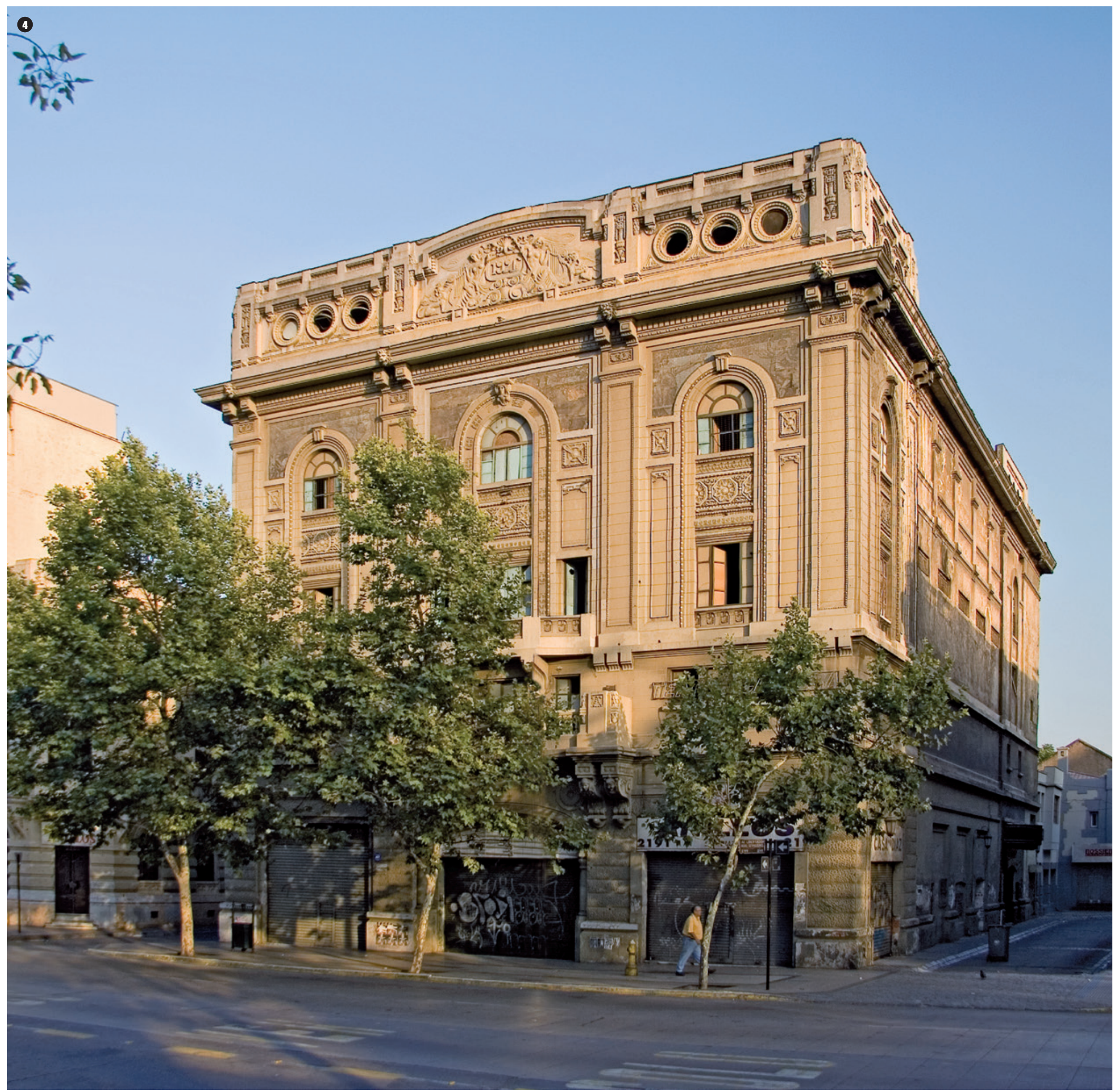


5. Planta: Foyer y camarines.

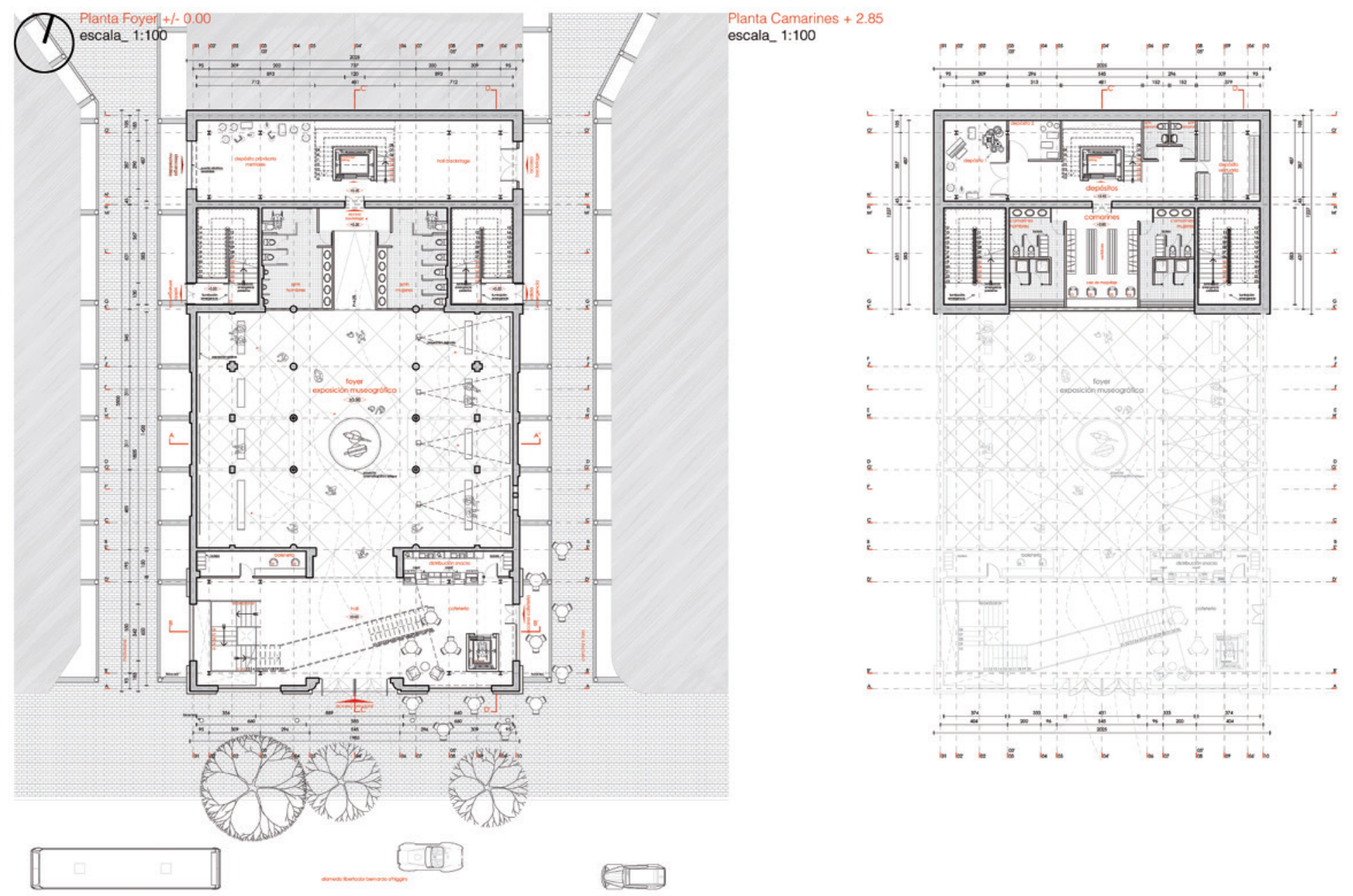

No obstante, varios autores establecen que "la solución no es, en caso alguno, momificarlos y justificar su pervivencia manteniéndolos en pie como piezas de un museo" (Sahady, 1996), sino que hay que sacarles el provecho explotando al máximo su potencial. Articulando la necesidad de rescatar un edificio antiguo -con historia y valor-y al mismo tiempo dotarlo de virtudes para el presente.
PROBLEMÁTICA 3. Orientación renovación urbana en centros históricos

A nivel urbano, "la obsolescencia física de los edificios, infraestructuras y espacios públicos, y la obsolescencia funcional de ciertas formas edificadas cuyos programas arquitectónicos y niveles de servicio no responden a las necesidades contemporáneas, son factores concurrentes en el proceso de abandono y deterioro de las áreas centrales" (Rojas, 2004).
De esta manera "se reduce el rendimiento de los impuestos inmobiliarios y los impuestos a los servicios con los que se financiaba el mantenimiento y mejoramiento de la infraestructura y los espacios públicos centrales" (Rojas, 2004), alimentando de forma cíclica el proceso de deterioro, abandono y cambios de uso. 
6. Planta: talleres audiovisuales, laboratorios restauración y platea.

\section{6}

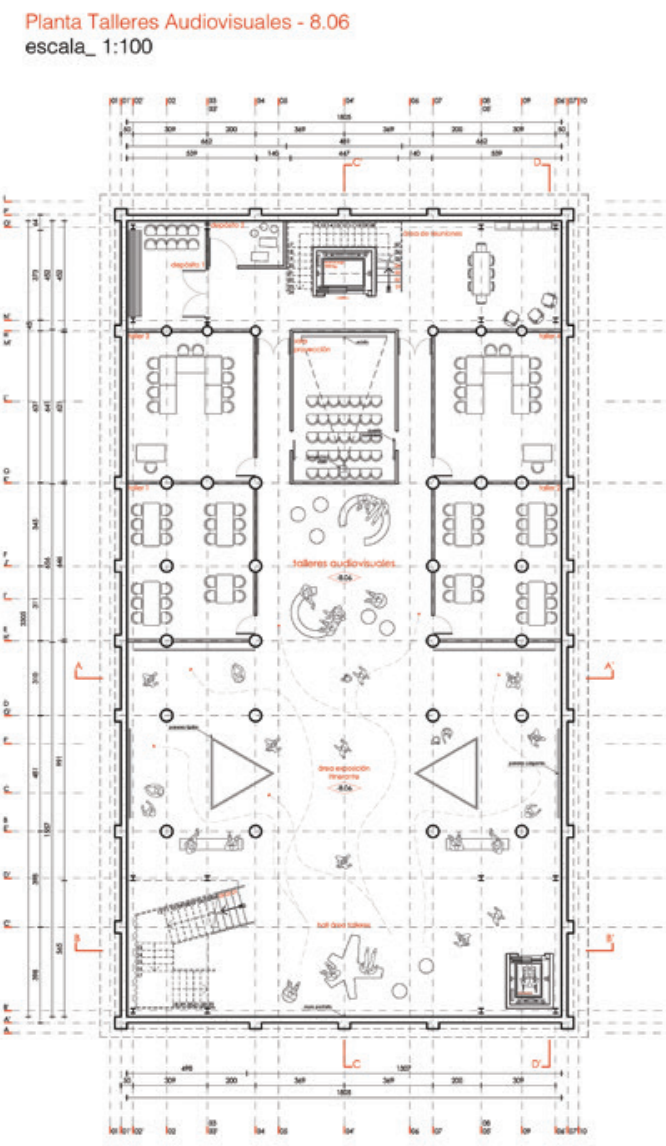

\section{TEMA | ENFOQUE TEÓRICO GENERAL}

Recuperación de inmuebles patrimoniales obsoletos como estrategia de revitalización urbana.

"El patrimonio nos plantea (...) el desafío de conservar las obras de valor incorporado desde una visión del presente de la ciudad histórica (...) Ello contribuirá a consolidar la identidad de nuestros asentamientos al mismo tiempo que incorporamos la modernidad" (Gebaver, 1993). Actualmente la idea de recuperar o dar nuevos
Planta Laboratorios Restauración - 4.03 escala_ 1:100

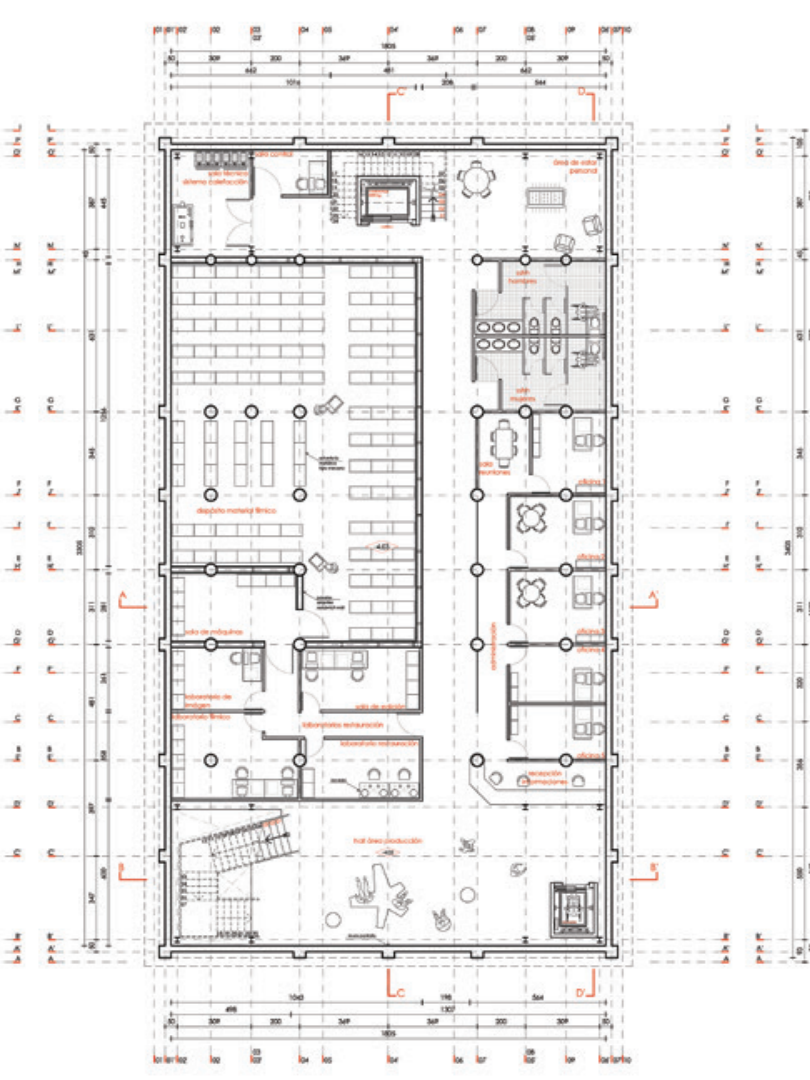

Planta Platea + 5.91

escala_ 1:100

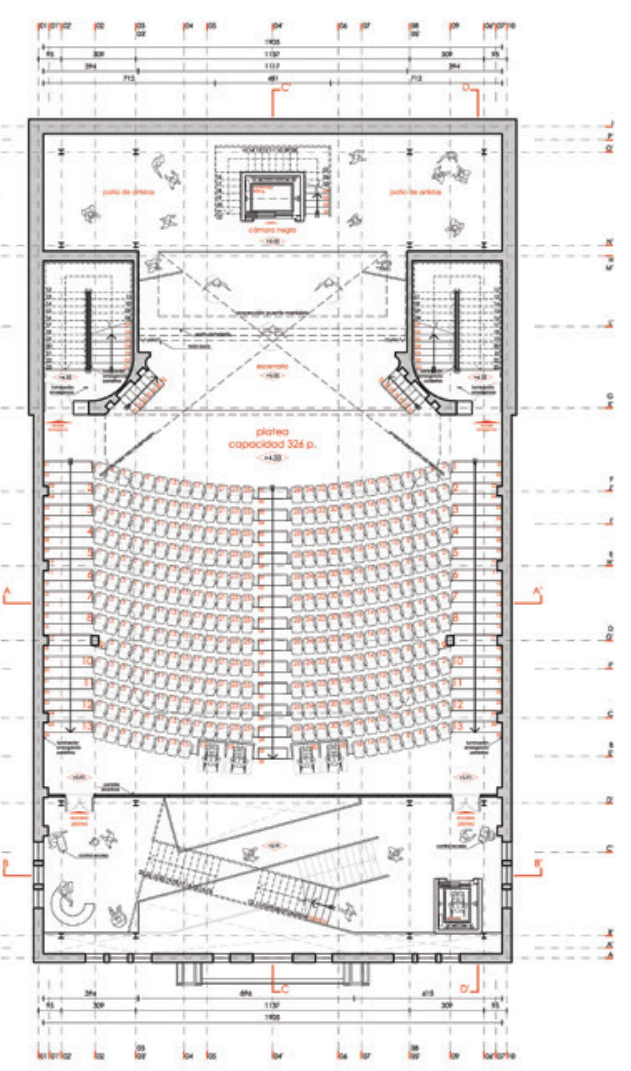

usos a cuerpos arquitectónicos existentes en estado de deterioro se ha hecho vigente, en términos prácticos como parte de estrategias de renovación urbana, como aprovechamiento de la estructura instalada o como reducción del gasto de la nueva obra; y en términos semánticos como reflejo del estado de conciencia de algunos sectores de la sociedad con relación al tema de la identidad de las comunidades y al interés por construir una memoria para la colectividad en consideración a la historia del lugar.
Los cines-teatros de barrio son reflejo del fenómeno sociocultural que vivía la comunidad por comienzos del siglo XX, constituyendo la tipología arquitectónica de carácter público que acogió a la masa en busca de entretención, dispersión e información, convirtiéndose en un lugar de encuentro cultural. Sin embargo, hoy estos espacios tienen un propósito muy distinto del cual fueron concebidos. Entre los que aún se mantienen en pie, hay algunos que son utilizados como bodegas, discotheques, templos religiosos o simplemente están abandonados. Actualmente, permanecen como cajas vacías de actividad y vitalidad urbana. 


\section{7}

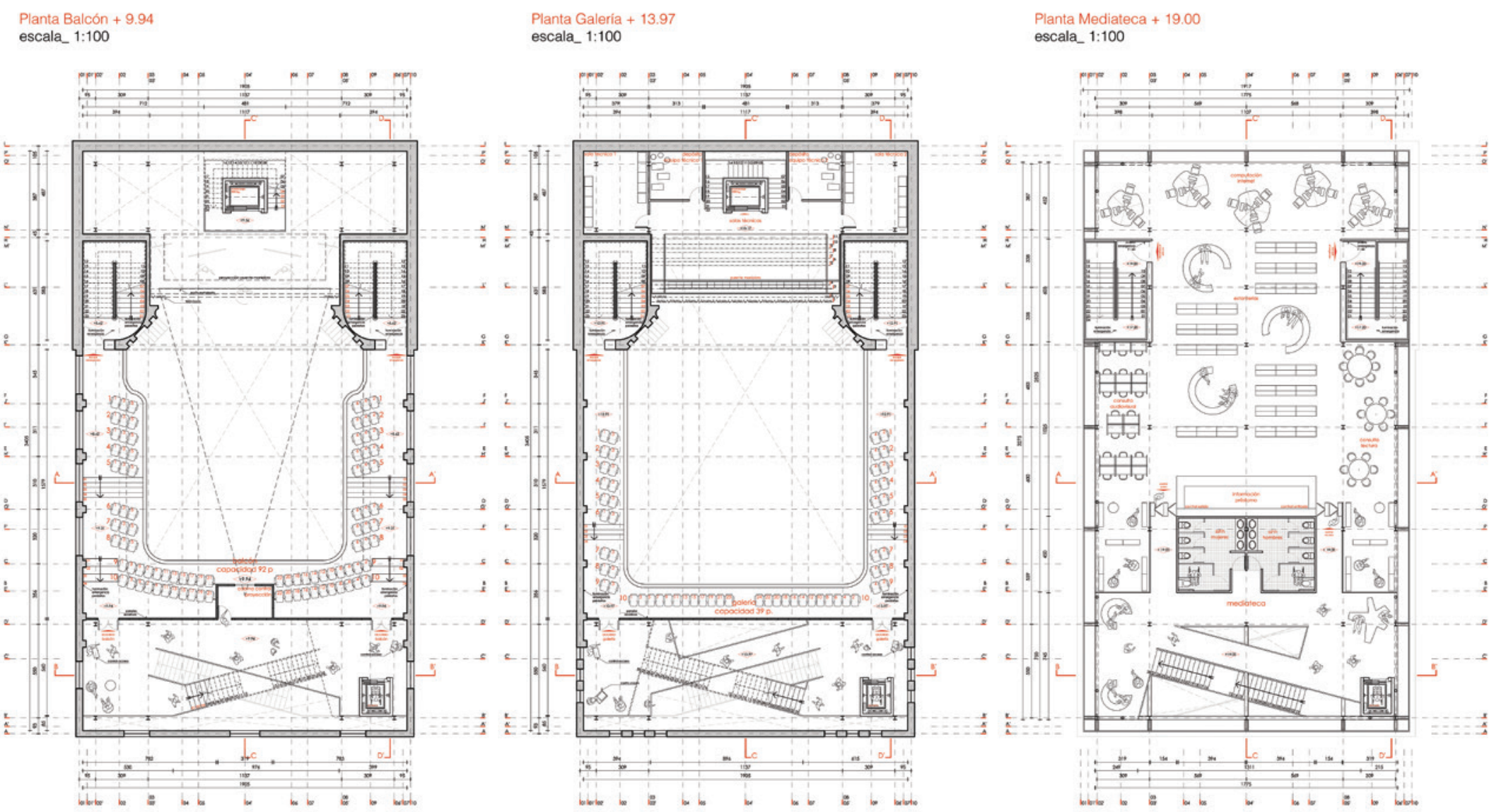

"El problema de las permanencias presenta dos vertientes: por un lado los elementos permanentes pueden ser considerados como elementos patológicos; por el otro, como elementos propulsores. O bien nos servimos de estos hechos para intentar comprender la ciudad en su totalidad o acabamos quedando atados por una serie de hechos que no podremos relacionar con el sistema urbano" (Rossi, 1986, p. 101). Por ello, es importante hacer una reflexión en torno a la función original de la edificación, si esta llegara a ser anacrónica, y su restauración solo permite una museificación -a excepción de las grandes de las grandes obras maestras de la arquitectura- la restauración no tiene mucho sentido. Personalmente, no me parece que tenga sentido el patrimonio por el patrimonio.

Es algo así como que "salvar los edificios antiguos ya no es suficiente: el objetivo no es la conservación, sino la transformación, un punto de vista más arquitectónico que sentimental o historicista de crear nuevas formas a partir de construcciones anteriores" (Powell, 1999). Como dijo Steven Greene (201 1, p. 31), "el edificio es nuevo una sola vez y por el resto de su vida estará sujeto a los cambios en el tiempo".

Producto de la noción temporal actual, la forma construida se relaciona con el tiempo, "aquello que ha conseguido llegar hasta hoy es actual, útil, contemporáneo. Y además te permite volver atrás en el tiempo, para seguir adelante. (...) Usar y volver a usar. Es como pensar y repensar las cosas. Y la arquitectura no es más que un modo de pensar la realidad" (Palmer, 2005, p. 9). 
8. Cortes A, B, C

9. Corte D.

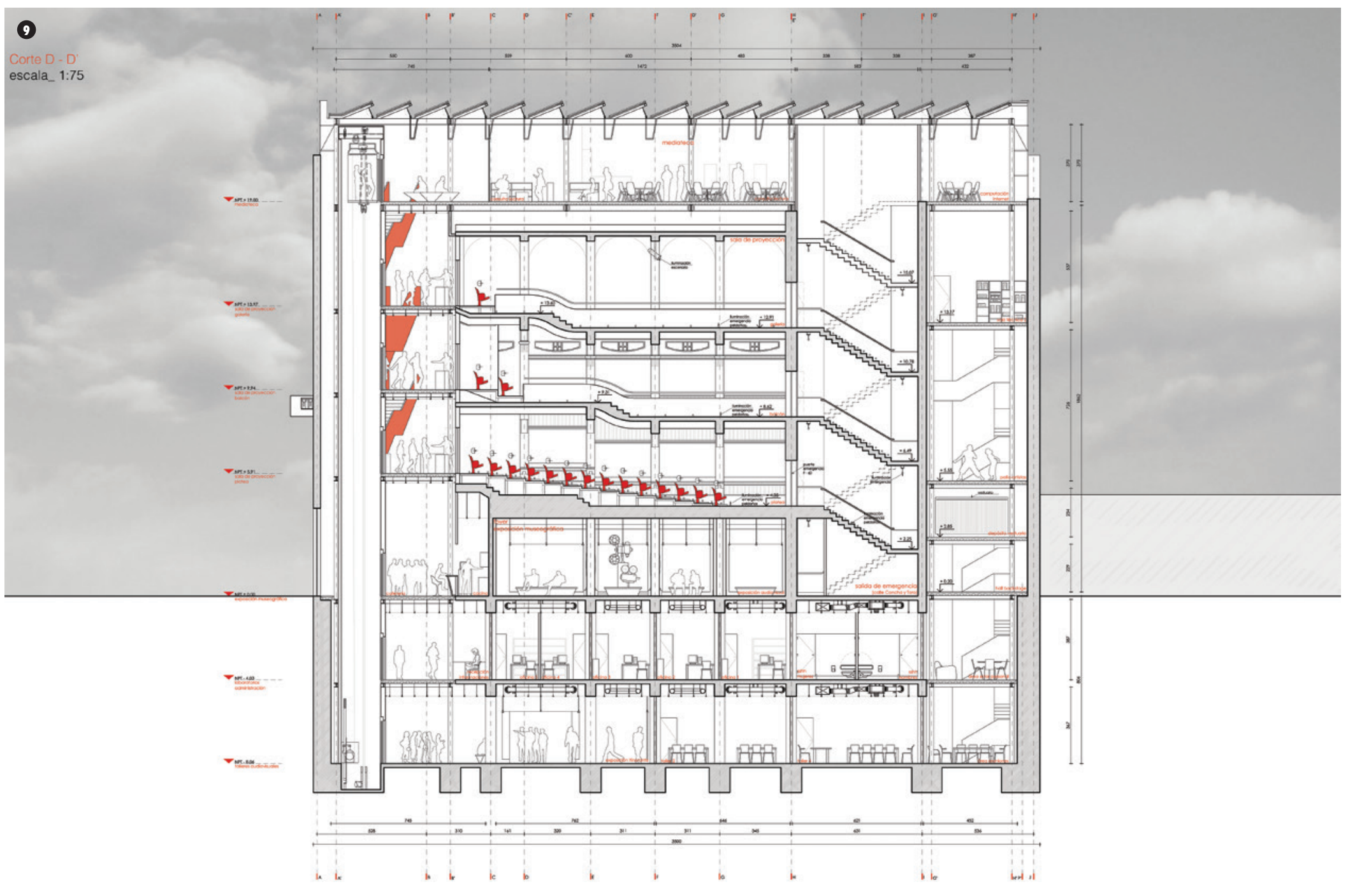

Es posible lograr de esta manera un mejor aprovechamiento de las estructuras existentes, tanto desde un punto de vista funcional activo, como de objetos relevantes de legado. La revalorización del inmueble puede darse de maneras más variadas y pueden ampliarse las posibilidades de usos, porque la estructura puede adecuarse a las necesidades.
Con el reciclaje se puede lograr que edificios de carácter tan determinado, como lo sería un cine-teatro, puedan modificarse de tal forma que logren cambiar su carácter y puedan acoger una actividad que antes no estaba contemplada, respetando sí la esencia del edificio y sus valores. El reciclaje parte de una base con contenido, con memoria, y es a partir de ahí de donde se empieza a intervenir y a transformar (de lo contrario, sería desconocer el edificio en el que se trabaja, y no es eso lo que se busca para los edificios patrimoniales).

\section{OBJETIVOS}

Desarrollar una propuesta que entregue una respuesta a la problemática que provoca la obsolescencia funcional que sufren algunos edificios históricos patrimoniales, de tal manera 
10. Elevación sur.

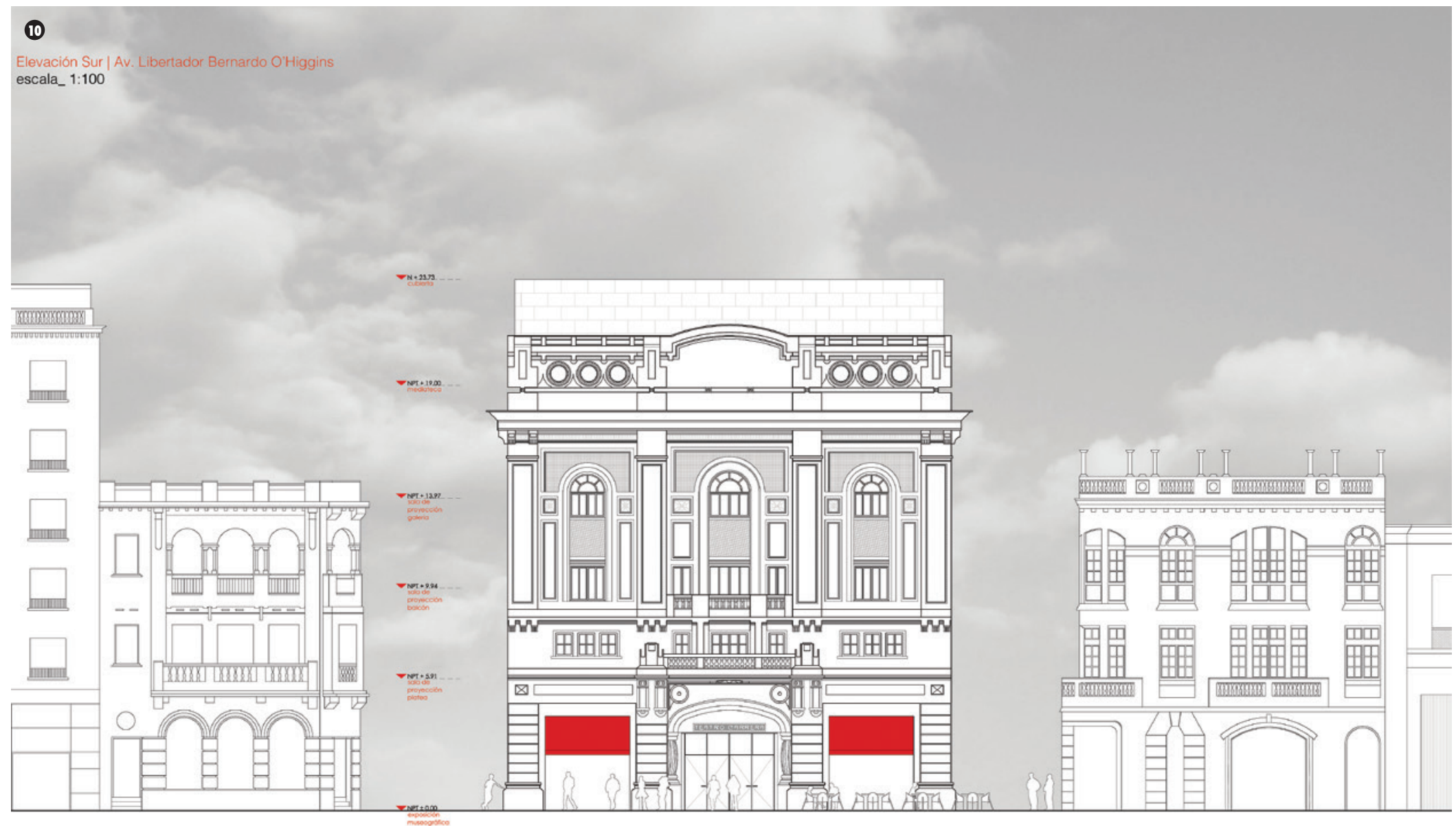

de reincorporarlo programática y especialmente a los requerimientos de la vida urbana actual.

Articular la necesidad de rescatar un edificio antiguo -con historia y valor-y al mismo tiempo dotarlo de virtudes para el presente, manifestando una postura antimuseística respecto a la restauración arquitectónica.

Cooperar con el proceso de revitalización urbana que vive el Barrio Concha y Toro, reviviendo uno de sus edificios icónicos pero olvidado; el Teatro Carrera.

\section{FUNDAMENTOS | CONCEPTOS}

Hoy a raíz del devenir de la actualidad y los cambios de la sociedad contemporánea algunos cines y teatros de barrio se encuentran obsoletos funcionalmente, llevándolos algunos a su destrucción o a su más completo desuso. Dicho esto, podemos inferir que las infraestructuras que perduran actualmente se encuentran en un estado de congelamiento temporal, sin un rol definido en la actividad urbana actual.
Es así, como se propone el desarrollo de un proyecto que nace bajo la premisa de la re-arquitecturización de estas estructuras obsoletas, es decir, someterlo a un fenómeno de transformación que permita reintegrarlo programática y físicamente a los requerimientos de la vida actual.

Toda re-arquitecturización toma como punto de partida una obra concreta, que en este caso es el Teatro Carrera. Esencialmente este edificio se puede definir como una "caja vacía", pero no en el sentido semántico, sino en el aspecto formal del elemento. Es decir, espacialmente el teatro se concibe como la envolvente de un vacío. 
11. Elevación oriente.

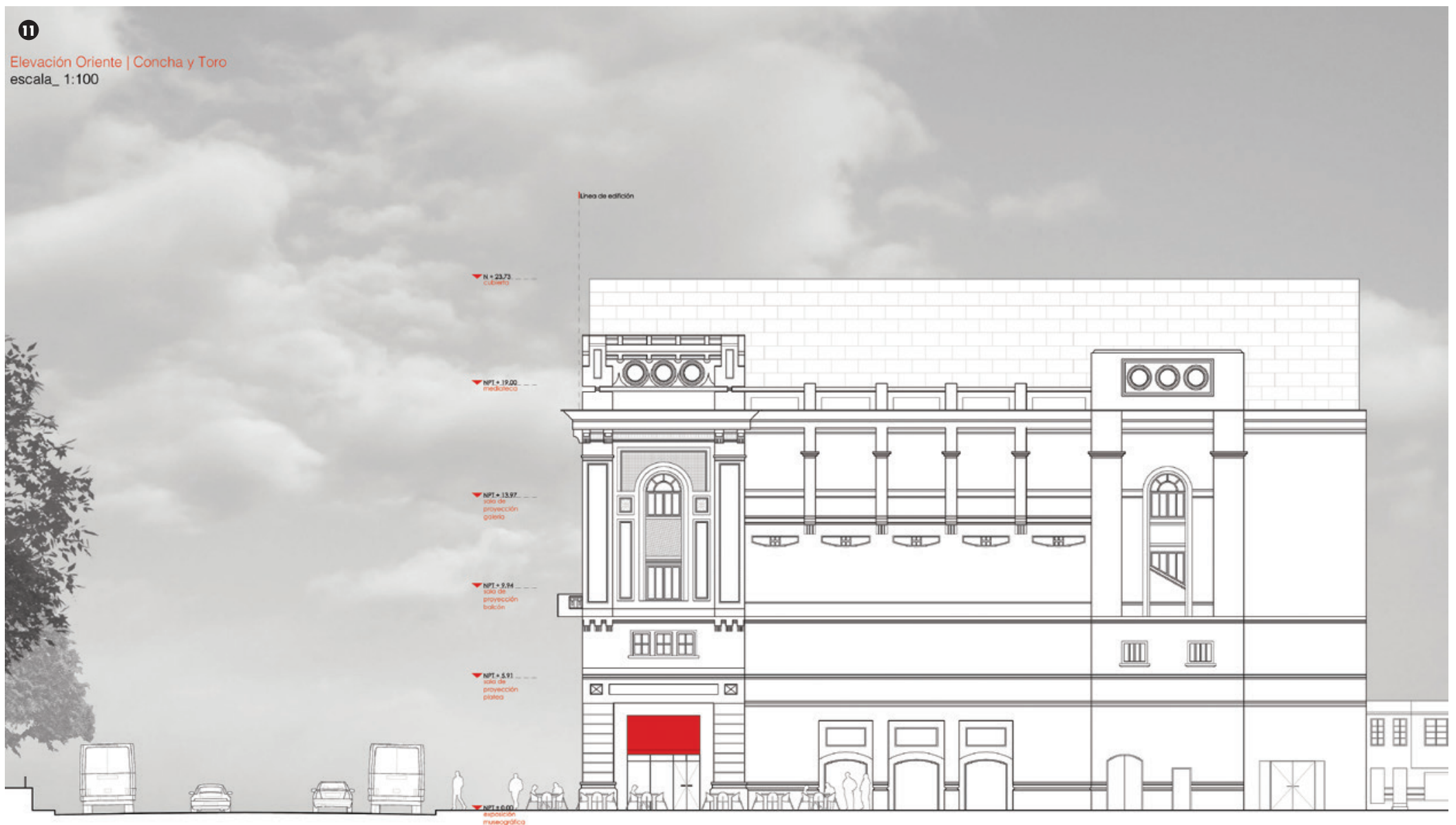

El edificio preexistente se ordena a partir de la relación contenedor-contenido (muros-vacío). Por lo tanto, la idea de transformación del edificio debe seguir esta misma lógica.

El proyecto se define y organiza a partir de capas o anillos que envuelven un núcleo preexistente y que a la vez se concentran dentro de una cáscara también existente. Entonces la intervención contemporánea se contiene entre el espacio definido por los límites del núcleo y la cáscara preexistente, en el "intersticio".

\section{PROPUESTA ARQUITECTÓNICA}

Se menciona anteriormente que el proyecto se organiza desde anillos programáticos, cuyos límites se definen a partir de elementos preexistentes; como núcleo se define la sala de proyección y como cáscara los muros perimetrales (fachadas).

Esta relación sigue la lógica del edificio preexistente CONTENEDOR-CONTENIDO.

\section{PROPUESTA URBANA}

Actualmente, el barrio vive un proceso de renovación urbana; nuevos proyectos y actividades culturales están activando un nuevo ciclo de vida, por lo que el Teatro Carrera no puede quedar atrás.

Arquitectónicamente, se plantea una rearquitecturización que permita reintegrarlo programática y físicamente a la vida de hoy. Sin embargo, el contexto es el encargado de 
$12,13,14$. Vistas interiores.

15. Vista exterior.
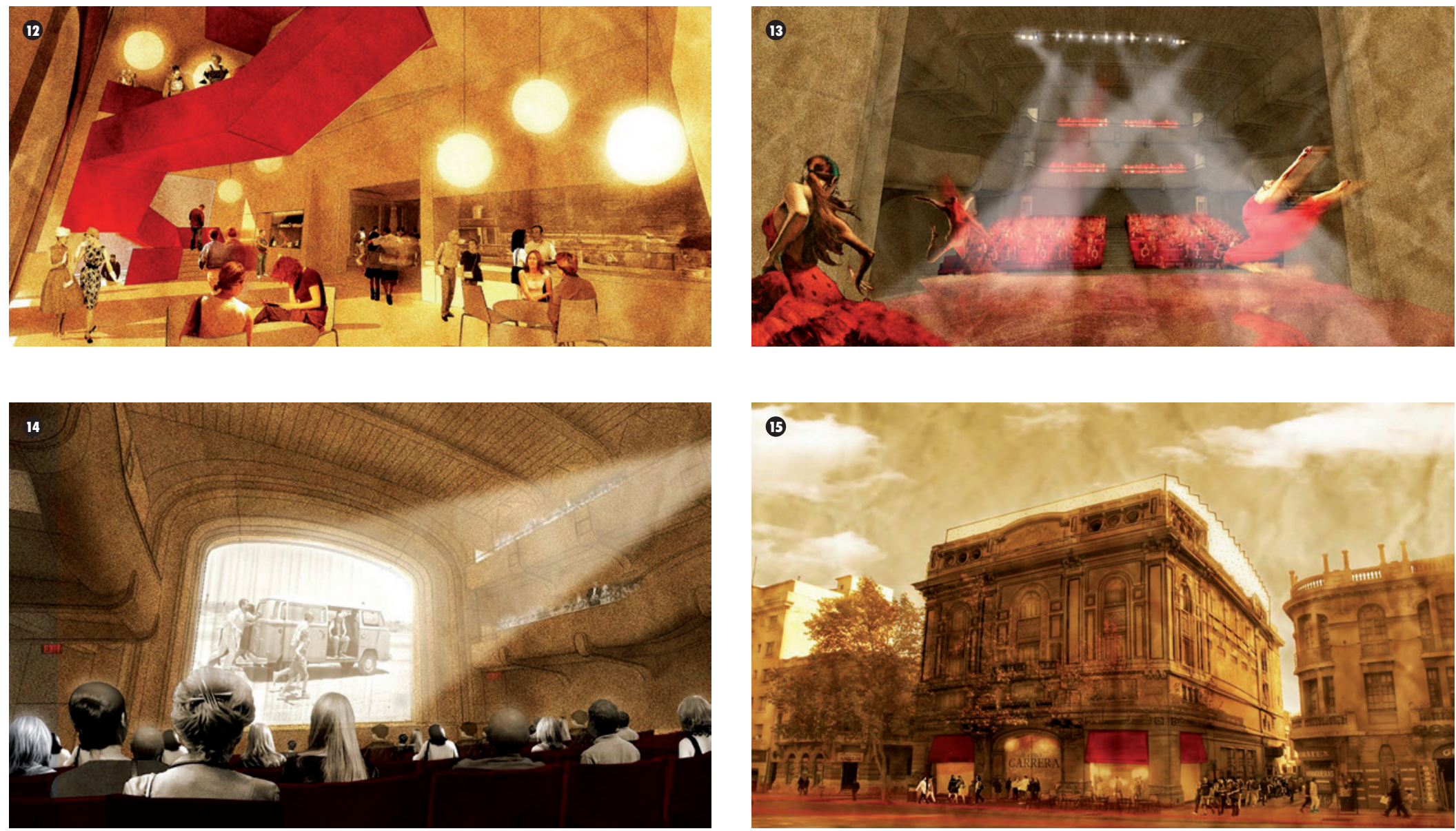

revalorar al edificio como punto de referencia y así, devolverle el carácter de activador social y urbano que una vez tuvo.

La directriz principal de la propuesta urbana consiste en sacar del olvido y el anonimato al edificio, e integrarlo a este renacer del barrio.

\section{BIBLIOGRAFÍA}

Gebayer, M. A. (1993). "Potencialidad del Patrimonio: Criterios de Intervención". CA n 74, Arquitectura del Norte Grande, Octubre/Noviembre/ Diciembre. Santiago: Publicación del Colegio de Arquitectos.

Greene, S. (2011). Permanence in Architecture. New Zeland: Master of Architecture, Victoria University of Wellington.

Palmer, M.(2005). "Editorial". Revista ARQ No59, El tiempo. Santiago: Ediciones ARQ, PUC.
Powell, K. (1999). El renacimiento de la arquitectura: la transformación y reconstrucción de edificios antiguos. Barcelona: Blume.

Rossi, A. (1986). La arquitectura de la ciudad. Madrid: Editorial Gustavo Gilli.

Rojas, E. (2004). Volver al centro. La recuperación de áreas centrales urbanas. Washington, D.C.: Banco Interamericano de Desarrollo.

Sahady, A. (1996). "Intervenciones Recientes en la Arquitectura del Pasado". CA n ${ }^{\circ} 83$, Remodelación y Reciclaje, Enero/Febrero/Marzo. Santiago: Publicación del Colegio de Arquitectos. 